\title{
CORRELATION BETWEEN THE MATURATION STAGES OF MANDIBULAR THIRD MOLARS AND CHRONOLOGICAL AGE IN PATIENTS VISITING SARDAR BEGUM DENTAL COLLEGE, PESHAWAR
}

Muhammad Ilyas ${ }^{1}$, Asma Khan ${ }^{1}$, Syed Murad Ali Shah ${ }^{1}$, Salman Khan ${ }^{1}$, Junaid Nadeem Malik ${ }^{1}$, 1. Sardar Begum Dental College Peshawar

\section{ABSTRACT:}

\section{OBJECTIVES:}

The objective of this study was to determine the correlation of chronological age with the maturation stages of mandibular third molar.

\section{METHODOLOGY:}

This descriptive, cross-sectional study was conducted at Sardar Begum Dental College, Gandhara University Peshawar on 384 patients from January 2018 to June 2018 and included patients having age 11-26 years with good quality Orthopantomogram showing mandibular third molar tooth germs bilaterally. Data were analyzed using SPSS version $22 p$-value $\leq 0.05$ was considered as statistically significant.

\section{RESULTS:}

Females 286 (74.5\%) were predominant than males 98 (25.5\%) with mean age presentation of $18.12 \pm 3.03$ years. The most frequent stage of Demirjian's stages of mandibular third molar was stage $F(24.7 \%)$. Pearson correlation showed that maturation stages of mandibular third molars were significantly related to the chronological age $(r=0.446, p$ value $=0.00)$.

\section{CONCLUSION:}

A correlation between maturation stages of mandibular third molars and chronological age existed.

\section{KEYWORDS:}

Age Estimation, Dental Age, Forensic Medicine, Tooth Development, Mandibular Third Molars

\section{INTRODUCTION:}

Forensic age estimation is used to facilitate the authorities in detecting unidentified victims, differentiation of cluster victims, establishing the

\begin{tabular}{c} 
Correspondence \\
Muhammad llyas \\
Department of Oral and Maxillofacial \\
Surgery \\
Sardar Begum Dental College, \\
Peshawar Email: \\
ilyas khan526@yahoo.com \\
\hline Phone: 0302-8809637 \\
https://doi.org/10.37762/jgmds.5-2.79
\end{tabular}
in dealing out undocumented refugees ${ }^{1,2}$. A number of methods are used to determine the chronological age of children and adults ${ }^{3}$. These methods are mainly divided into two main groups: (a) bone maturation and (b) tooth development ${ }^{4}$.

The bone maturation method is primarily based on radiographs of specific structures such as epiphysis-diaphysis fusion of long bones, medial extremity of the clavicle, epiphyseal head of the first rib, anterior iliac crest at the epiphyseal union and fusion of the sphenoid bone with basilar part of the occipital bone. However, the drawback of bone maturation method is that these processes are completed roughly around the age of eighteen years which is quite early as compared to the third molar development and maturation, which continues until the early twenties ${ }^{3,5}$. Therefore, stages of calcification of third molar is one of the tools that can be used as predictor of the chronological age $e^{3,6,7}$.

A variety of classifications mainly based on numerical values and grading systems have been put forward by different authors but they were difficult to distinguish from one another ${ }^{2,8,9}$. Demirjian et al. ${ }^{10}$ proposed a classification that involves, identifying only four stages for development of crown (stages A-D) and four root developmental stages $(E-H)$ thus avoids numeric 
identification of stages and minimizing the possibility of suggesting more than one stage representing the processes of the same duration. Third molars have large variation in the development, calcification and eruption timings. Calcification of third molar starts at about seven years, formation of enamel ranges from 12-18 years and completion of root formation between 18-25 years. Development and eruption of mandibular third molar varies with the ethnicity of individuals. In Western countries, eruption of third molars range 17 to 21 years, in Africans 15 to 19 years and in Asian 21.49 to 23.34 years of ages $^{8,11}$. However, there is scarcity of research in Pakistan in which correlation of the maturation stages of mandibular third molar with the chronological age was demonstrated. Therefore, a research may require correlating maturation stages of mandibular third molar with chronological age that will help in the assessment of age in our population for forensics and medico-legal purposes. The aim of this study was to determine the correlation of the maturation stages of mandibular third molar with the chronological age.

\section{METHODOLOGY:}

A descriptive cross-sectional study was carried out in the Department of Orthodontics, Sardar Begum Dental College and Hospital, Peshawar from January 2018 to June 2018. A total of 384 patients were selected through convenience sampling technique using WHO formula for sample selection.

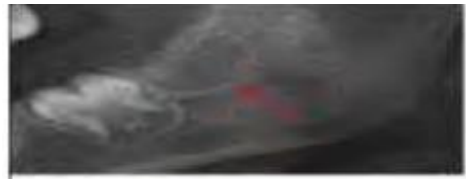

Stage 1

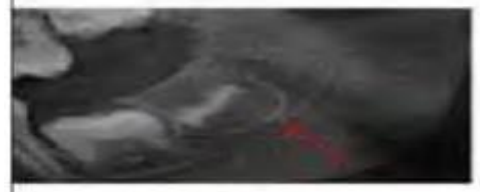

Stage 4

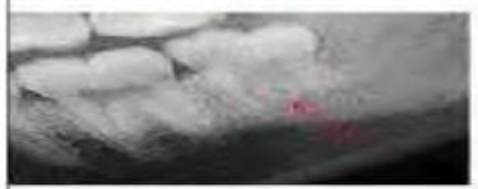

Stage 7

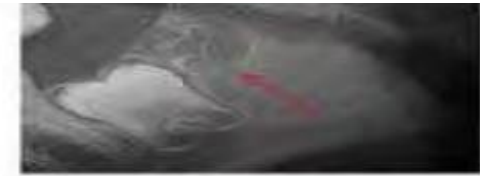

Stage 2

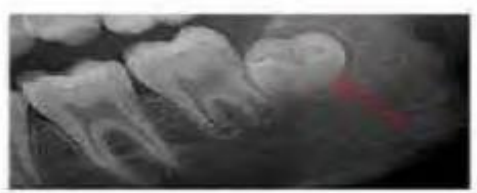

Stage 5

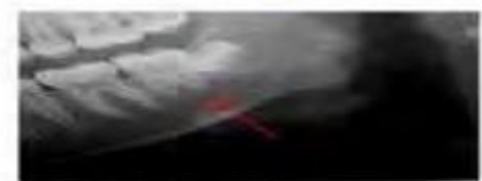

Stage 8
$N=Z^{2}(P)\{1-P\} / d^{2}$

$Z=Z$ statistic for level of confidence $(95 \%)=1.96$,

$\mathrm{P}=$ Prevalence $/$ frequency, $\mathrm{D}=$ Precision $=5 \%$,

$\mathrm{P}$ is taken $50 \%$ as the population statistic could not be found. This study included patients having age 11-26 years with good quality Orthopantomogram showing mandibular third molar tooth germs bilaterally. Hypodontia / oligodontia / amelogenesis imperfecta / dentinogenesis imperfecta, history of trauma / fracture in third molar region and patients with any systemic disease were excluded from this study. After the approval of Ethical Review Committee of Gandhara University, a welldocumented proforma was used in which patient's bio-data and informed consent was taken. OPG radiograph was examined over the radiograph illuminator and stage of maturation of mandibular third molar tooth germ was determined and charted down on a proforma. The stages of maturation according to Demirjian's method ${ }^{10}$ is given in Figure 1. Data were analyzed using SPSS version 22. Descriptive statistics were applied for gender, age and Demirjian's stages. Pearson correlation was used for the correlation between the chronological age and stages of maturation of mandibular third molars. The level of significance was kept at $p \leq 5$. 0.05.

\section{RESULTS:}

The mean age presentation was $18.12 \pm 3.03$ years. Out of total of 384 patients, 286 (74.5\%) were females and $98(25.5 \%)$ were males with ratio of 2.9:1. The percentage of Demirjian's stages of mandibular third molar development is

Figure 1: Stages of Demirjian's Method Based on the Development of Mandibular Third Molar ${ }^{10}$ 
shown in figure 2 while frequency is given in Table 1. The Pearson correlation showed that there was correlation between Demirijian's stage of third molar and chronologic age $(r=0.446)$ which were statistically significant ( $p$ value $=$ $0.00)$.

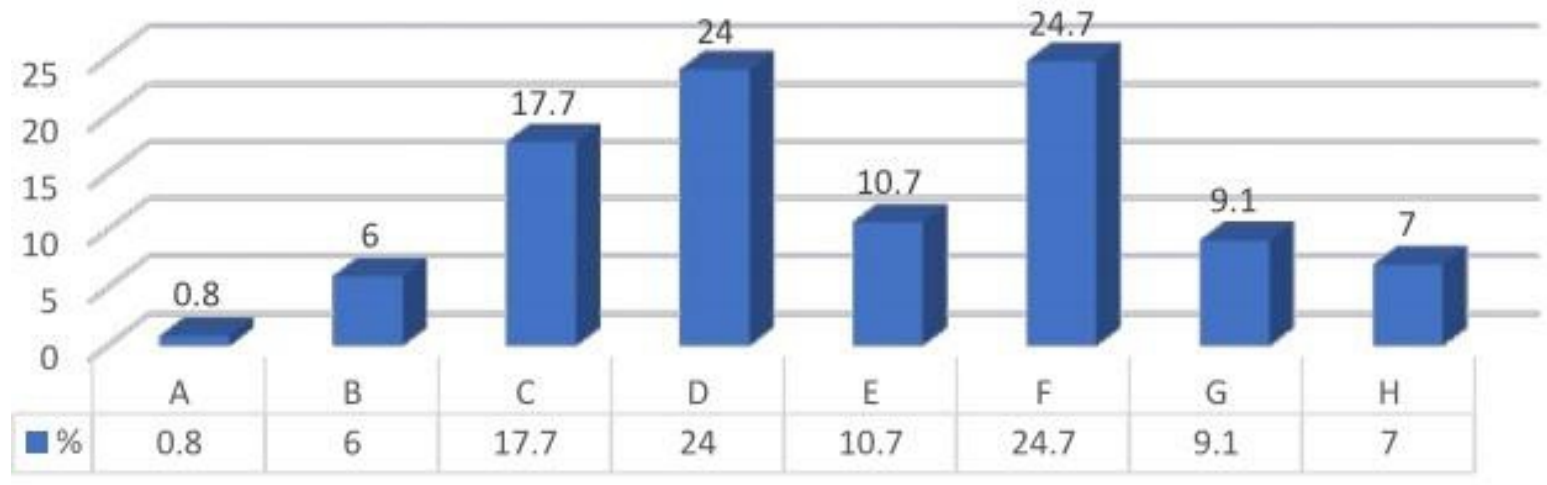

Figure 2: Percentage of Demirjian's Stages of Mandibular Third Molar

Table 1: Frequency of Demirjian's Stages of Mandibular Third Molar Stratified by Age

\begin{tabular}{|c|c|c|c|c|c|c|c|c|c|}
\hline \multirow{2}{*}{ Age } & \multicolumn{8}{|c|}{ Demirjian's Stage of Mandibular Third Molar } & \multirow{2}{*}{ Tota } \\
\hline & A & B & C & D & $\mathbf{E}$ & $\mathbf{F}$ & G & $\mathbf{H}$ & \\
\hline 11.00 & 0 & 0 & 4 & 0 & 0 & 0 & 0 & 0 & 4 \\
\hline 13.00 & 0 & 0 & 0 & 0 & 0 & 4 & 0 & 0 & 4 \\
\hline 14.00 & 0 & 0 & 0 & 0 & 0 & 4 & 0 & 0 & 4 \\
\hline 15.00 & 0 & 12 & 19 & 16 & 0 & 11 & 4 & 0 & 62 \\
\hline 16.00 & 3 & 4 & 25 & 32 & 12 & 8 & 0 & 0 & 84 \\
\hline 17.00 & 0 & 3 & 8 & 12 & 8 & 12 & 0 & 0 & 43 \\
\hline 18.00 & 0 & 0 & 0 & 11 & 7 & 7 & 0 & 3 & 28 \\
\hline 19.00 & 0 & 0 & 8 & 7 & 0 & 16 & 3 & 8 & 42 \\
\hline 20.00 & 0 & 0 & 0 & 3 & 0 & 8 & 0 & 0 & 11 \\
\hline 21.00 & 0 & 4 & 0 & 0 & 6 & 10 & 3 & 16 & 39 \\
\hline 22.00 & 0 & 0 & 0 & 7 & 0 & 11 & 7 & 0 & 25 \\
\hline 23.00 & 0 & 0 & 0 & 0 & 0 & 4 & 11 & 0 & 15 \\
\hline 24.00 & 0 & 0 & 4 & 0 & 4 & 0 & 4 & 0 & 12 \\
\hline 25.00 & 0 & 0 & 0 & 4 & 4 & 0 & 0 & 0 & 8 \\
\hline 26.00 & 0 & 0 & 0 & 0 & 0 & 0 & 3 & 0 & 3 \\
\hline Total & 3 & 23 & 68 & 92 & 41 & 95 & 35 & 27 & 384 \\
\hline
\end{tabular}

\section{DISCUSSION:}

In the current study the age range was set at 11 to 26 years in order to do full estimation of each mineralization stage. Ajmal et al $^{12}$, conducted a study in which age estimation using third molar teeth on Southern Saudi population was used. They took age range of 13 to 23 years in their study which is consistent with this study. Solari and Abramovitch $^{13}$, reported that the mean age for "Stage H" was 20.5 years. However, the mean age could be lower if the population sample age range was limited to a younger age less than 24 years. Thus, they suggested that the upper age limit for population samples in future studies should not be greater than 22 years. According to Robetti et $\mathrm{al}^{14}$ at 18 years of age, all permanent teeth have completed their root formation with closed apices, except the third molars. Third molar teeth offer the only possibility for dental age estimation between 16 and 22 years of age. In the present study females were more in number than males. The 
reasons may be religious, and males have a higher education than females so they are more cautious about their oral hygiene. In this study, consecutive sampling was done which can be another reason. A study by Pnyadharshini et $\mathrm{al}^{4}$, reported a sample of 848 subjects, of which 471 $(55.4 \%)$ were males and 377 (44.5\%) were females in South Indian population in which age estimation using development of third molars was used. These results contradict this study results. This study showed no specific age for particular tooth stages were present. In the present study, "Stages D \& E" were in range from 15 to 25 years. "Stage F" was extended from 13 to 23 years of age. "Stage G" was extended from 15 to 26 years of age. "Stage H" was from 18 to 21 years. Therefore, age is a good indicator of biologic when assessed based on Demirjian's method. This is in agreement with other studies $^{15-18}$

\section{CONCLUSION:}

The maturation stages of mandibular third molars were significantly related to the chronological age.

\section{LIMITATIONS:}

The limitation of this study was its sample size with no equal gender proportions. The patients selected were from one department only and may not predict the sample size of the community. Moreover, the stages of the Demirjian's method of mandibular third molar maturation showed a range of chronological age. Apart from these, this study thoroughly demonstrated the stages of mandibular third molar maturation, age range with maturation stage and correlation of age with maturation stage is uniqueness to our study.

\section{CONFLICT OF INTEREST:}

Conflict of interest is declared with research topic and not among authors.

\section{REFERENCES:}

1. Manjunatha BS, Soni NK. Estimation of age from development and eruption of teeth. $\mathrm{J}$ Forensic Dent Sci. 2014;6(2):73-6. doi: 10.4103/0975-1475.132526.

2. Panchbhai AS. Dental radiographic indicators, a key to age estimation. Dentomaxillofac Radiol. 2011:40(4):199-212. doi: $10.1259 / \mathrm{dmfr} / 19478385$.

3. Qing M. Qiu L. Gao Z. Bhandari K. The chronological age estimation of third molar mineralization of Han population in South-
Western China. J Forensic Leg Med. 2014;24:24-7. 10.10160jftm.2014.03.004.

4. Priyadharshini KI, Idiculla JJ. Sivapathasundaram B, Mohanbabu V. Augustine D. Pate S. Age estimation using development of third molars in South Indian population: a radiological study. J Int Soc Prey Community Dent. 2015;5(Suppl 1): S32-8. doi: 10.4103/2231-0762.156522.

5. Talla MV. Adamala SR. SurapaneN S. Chilakuru D. Mandibular third molar germination: a ram anomaly. J Indian Mad Oral Med Radiol. 2015;27(2):241-4. dot 10.4103/0972-1363.170145.

6. Abu Asab S. Noor SN. Khamls MF. The accuracy of Dermirjian method in dental age estimation of Malay children. Singapore Dent J. 2011;32(1):19-27. doi: 10.1016/S0377- 5291(12)70012-3.

7. Olze A. Ishikawa T. Zhu BL. Schulz R. Heinecke A. Maeda $H$. et al. Studies of the chronological Cane of wisdom tooth eruption in a Japanese population. Forensic Sci Int. 2008:174(2-3):203-6.

8. Priyadarshini C. Puranik MP. Urea SR. Dental age estimation methods: a review. Int J Adv Health Sd. 2015;1(12):19-25.

9. Jayaraman J, King NM. Roberts GJ, Wong HM. Dental age assessment: are Demirjian's standards appropriate for southern Chinese children? J Forensic Odontostomatol. 2011;29(2):22-8.

10. Demirjian A, Goldstein H, Tanner JM. A new system of dental age assessment. Hum Biol. 1973;45(4211-27.

11. TeMoananui R. Kieser JA, Herbison GP. Liversidge HM. Estimating age in Maori, Pacific Island and European children from New Zealand. J Forensic Sci. 2008:53(2):401-4. doi: 10.1111/j.1556 4029.2007.00643.x.

12. Ajmal M. Assin KI. Al-Ameer KY. Assid AM, Luqman M. Age estimation using third molar teeth: a study on southern Saudi population. J Forensic Dent Sci. 2012;4(2):63-5. doi: 10.4103/0975-1475.109886

13. Solari AC, Abramovitch K. The accuracy and precision of third molar development as an indicator of chronological age in Hispanic s. J Forensic Sci. 2002;47(3):531-5.

14. Robetti I, lorio $M$, Dalle Molle $M$. Orthopantomography and the determination of majority age. Panminerva Med. 1993;35(3):170-2.

15. Franklin D, Flavel A, Noble J, Swift L, Karkhanis $S$. Forensic age estimation in living individuals: methodological considerations in the context of medico-legal practice. Res Rep Forensic Med Sci. 
2015;5:53-66. doi: 10.2147/RRFMS.S75140.

16. Cattaneo C, Obertova Z, Ratnayake M, Marasciuolo L, Tutkuviene J, Poppa P, et al. Can facial proportions taken from images be of use for ageing in cases of suspected child pornography? a pilot study. Int J Legal Med. 2012;126(1):139-44. doi: 10.1007/s00414011-0564-7.

17. Carpenter B, O'Brien E, Hayes S, Death J.
Harm, responsibility, age, and consent. New Criminal Law Rev: Int Interdisciplinary J. 2014;17(1):23-54 .

10.1525/nclr.2014.17.1.23.

18. Jurca A, Lazar L, Pacurar M, Bica $C$, Chibelean M, Bud E. Dental age assessment using Demirjian's method: a radiographic study. Eur Sci J. 2014;10(36):51-60.

\section{CONTRIBUTORS}

1. Muhammad llyas - Concept \& Design; Data Acquisition; Drafting Manuscript; Critical Revision

2. Asma Khan - Concept \& Design; Data Acquisition; Data Analysis/Interpretation

3. Syed Murad All Shah - Critical Revision; Supervision; Final Approval

4. Salman Khan - Data Acquisition

5. Junaid Nadeem Malik - Data Acquisition

LICENSE: JGMDS publishes its articles under a Creative Commons Attribution Non-Commercial Share-Alike license (CC-BY-NC-SA 4.0) COPYRIGHTS: Authors retain the rights without any restrictions to freely download, print, share and disseminate the article for any lawful purpose. It includes scholarly networks such as Research Gate, Google Scholar, LinkedIn, Academia.edu, Twitter, and other academic or professional networking sites. 